\title{
Research on FBG-Based Sensor Networks and Their Coexistence with Fiber Optical Transmission Systems
}

\author{
Ugis Senkans $\mathbb{D}$, Janis Braunfelds $\mathbb{D}$, Ilya Lyashuk, Jurgis Porins, Sandis Spolitis $\mathbb{D}$, \\ and Vjaceslavs Bobrovs
}

Institute of Telecommunications, Riga Technical University, Azenes St. 12, LV-1048 Riga, Latvia

Correspondence should be addressed to Janis Braunfelds; janis.braunfelds@rtu.lv

Received 2 May 2019; Revised 6 August 2019; Accepted 28 August 2019; Published 6 November 2019

Academic Editor: Carlos Ruiz

Copyright (C) 2019 Ugis Senkans et al. This is an open access article distributed under the Creative Commons Attribution License, which permits unrestricted use, distribution, and reproduction in any medium, provided the original work is properly cited.

\begin{abstract}
Market forecasts and trends for the usage of fiber optical sensors confirm that demand for them will continue to increase in the near future. This article focuses on the research of fiber Bragg grating (FBG) sensor network, their applications in IoT and structural health monitoring (SHM), and especially their coexistence with existing fiber optical communication system infrastructure. Firstly, the spectrum of available commercial optical FBG temperature sensor was experimentally measured and amplitudefrequency response data was acquired to further develop the simulation model in the environment of RSoft OptSim software. The simulation model included optical sensor network, which is combined with 8-channel intensity-modulated wavelength division multiplexed (WDM) fiber optical data transmission system, where one shared $20 \mathrm{~km}$ long ITU-TG.652 single-mode optical fiber was used for transmission of both sensor and data signals. Secondly, research on a minimal allowable channel spacing between sensors' channels was investigated by using MathWorks MATLAB software, and a new effective and more precise determination algorithm of the exact center of the sensor signal's peak was proposed. Finally, we experimentally show successfully operating coexistence concept of the spectrum-sliced fiber optical transmission system with embedded scalable FBG sensor network over one shared optical fiber, where the whole system is feed by only one broadband light source.
\end{abstract}

\section{Introduction}

As it is observed in [1], fiber optical sensors are commonly used to measure a wide range of physical parameters, for example, temperature, strain, vibration, mechanical deformation, and pressure. Sensors that are based on a fiber Bragg grating (FBG) technology are one of the most promising and are widely used mainly due to their significant advantages like small size, high sensitivity, remote sensing capabilities and provided immunity to electromagnetic (EM) interference, etc.

From a physical point of view, the FBG is small (typically few centimeters in length) optical fiber span that is created by introducing a modulation of its core effective refractive index. To develop such grating, few methods can be used, as shown, for instance, in [2] - direct point-bypoint method, continuous core-scanning method, or inter- ferometric method. As a result, the FBG will reflect signals with specific central frequency or wavelength, called Bragg wavelength. Another aspect of fiber optical sensors is their adaptability as it is confirmed in [3] that glass optical fibers are more suitable for data transmission than polymer optical fibers. That is due to their smaller attenuation and higher bandwidth capabilities.

However, besides the important advantages, according to the article [1], FBG optical sensors have some disadvantages that can be triggered by crossed sensitivity providing inaccurate measurements of strain or temperature. Parallel to that, as it is discussed in the article [4], a risk factor can also be areas with high temperatures and places where vibration or trembling is observed near the optical fiber sensors.

For a couple of years until now, the need for fiber optical sensors globally is continuously rising. From the analysis of current trends of fiber optical sensor market 
shown in an article [1], especially highlighting the FBG, it is clear that there are three main segments leading to the demand for fiber optical sensors. One of them is sensing devices-optical sensors as a technology for different sensing applications. Another one is instrumentation, for example, software, acquisition systems, interrogation devices, and graphical interfaces. The third segment is system integration and installment services, for example, engineering projects.

Nowadays, lots of different fields, for example, structural health monitoring (SHM), have a wide variety of possible optical sensor installation and deployment methods. For instance, there are applications evaluated [5] where FBG optical sensors are embedded in concrete to measure strain and monitor tracks. According to [6], topical research theme in a matter of SHM is also an underground coal mine monitoring due to the occurring construction accidents. Furthermore, studies have shown [7] implementation of optical sensors in different surfaces and materials, like 3D-printed structures, where $3 \mathrm{D}$ printing technology can serve as a link to connect FBG optical sensors and robotic devices. Last but not least, in the latest studies [8], particular interest is in sensing applications for supertall buildings that might be in a risk of different types of deformations, hence a threat for civil security.

Considering a wide variety of reports that are based on a fiber optical market research [9], the newest statistics predict average annual growth of the sensor market in the range between $4.41 \%$ and $10.5 \%$. These numbers are acquired by combing a different kind of optical sensor types such as [10] point, distributed, quasidistributed, intensity, phase, polarization, frequency, physical, chemical biomedical ones, and different categories that are based on sensing location, operating principle, and applications.

Due to the growth in the number of devices using available transmission spectrum for communications and data transmission as well as enhancement of optical networks infrastructure, literature in $[11,12]$ has shown an indication that there is increased attention on effective spectrum utilization. One of the key elements in the deployment of sensor networks is an effective choice of their minimal channel spacing to keep spectral efficiency of sensor network high as possible and to avoid overlapping of adjacent optical sensor signals that leads to the need for developing algorithms for precise determination of the exact center of the sensor signal's peaks (also called as central frequency or wavelength). Changes in measured central frequency or wavelength of the sensor's reflected signal are representing the variation of physical parameters such as temperature and strain. Another key element, which is as important as the first one, is ensuring resource-effective architectures of data transmission and sensing systems, maximizing their compatibility. Therefore, our experimental fiber optical transmission system with embedded FBG sensor network, as shown in Section 4 of this paper, operating over one shared optical distribution network (single-mode optical fiber), while using unified broadband light source for both systems, serves as a good example of the coexistence of these systems. To the best of our knowledge, such experiments for the implementation of unified light source have not been conducted yet.

\section{Fiber Optical Sensors in IoT and SHM Applications}

Internet of Things (IoT) is an area of potential growth and different kinds of innovations which agrees the majority of the world's governments in Europe, America, and Asia. As indicated in [13], public safety, environmental protection, and Smart Industries, e.g., smart homes, are only a few of the potential IoT application areas. As mentioned in studies like [14, 15], SHM applications can be an important field of fiber optical sensor usage as well as for the domain of IoT in cases of optical sensor implementation for operational safety of structure (e.g., buildings, roofs, bridges) observations. The authors can suggest one of the many ways of the possible scenarios, which links the IoT with SMH. From a wide variety of modern technology research, one of them, for instance, which is carried out in IoT direction, is smart cars and traffic control. In this case, one of the scenarios includes IoT smart car combination together with fiber optical sensing for SHM needs. In the scenario when there are roads with embedded FBG optical sensors, providing strain measurements for road SHM, this information can be provided through the nearly deployed single-mode optical fiber cable to the service provider central office for further processing. All the strain measurements can be processed to detect the streets which at that particular moment have traffic jams and by knowing that, a traffic control optimization could be initiated. Such information, for example, traffic jam situation and traffic safety information, could be as well wirelessly transmitted to IoT smart cars, which then could take alternative routes.

By taking a closer look on a sensing layer, [16] presents that it can be seen that a layer is made of different types of control modules, for instance, sensor networks that include particular kind of sensors needed for monitoring of vibration, strain, temperature, humidity, etc. As for the main information, it is collected in the perception level and sensing layer comprises a data acquisition as well as a short-distance transmission where data and information is aggregated via sensing devices and later handed over to the particular gateway by bus or short-distance wireless transmission technology applications.

To ensure high safety of civil infrastructures, such as buildings, bridges, roads, and even road embankments, assessment of structural integrity in relation to the loadcarrying capacity, which decreases due to aging, damage, or deterioration, must be carried out continuously. Studies [17] have previously shown that traditionally this structural health monitoring is carried out by periodic visual investigations, or by using discrete electrical or mechanical sensors. However, such sensor deployment is time-consuming and they are difficult to install during construction and repairs. They require a large number of electrical connections and complex cabling and have a high susceptibility to electromagnetic interference (EMI), humidity, and relatively short lifetime.

As an example, currently, in Latvia, SHM of bridges, roads, railways, and surrounding embankments is mostly done through visual inspections. Latvia is a good example 


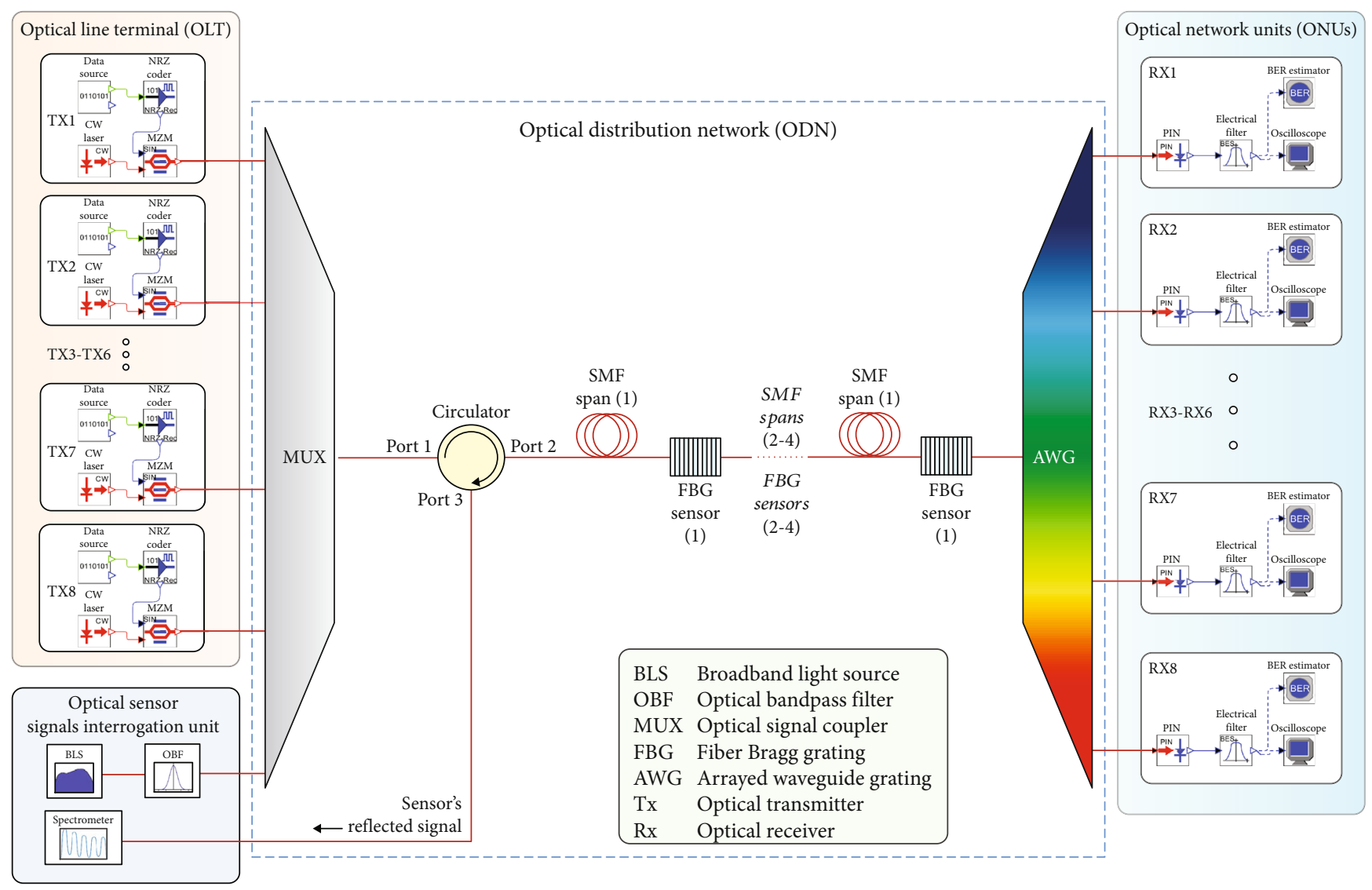

FIGURE 1: Developed simulation model of combined 5 FBG temperature sensor networks integrated into 8-channel 10 Gbit/s NRZ-OOK WDM-PON transmission system.

in successful fiber optical network rollout and holds the leadership position in the European fiber to the home (FTTH) ranking, with fiber coverage of $45.2 \%$. Therefore, due to the availability of fiber optical infrastructure, fiber optical sensors are paying large attention from Latvian companies like the national road administration-State Joint Stock Company "Latvian State Roads" [18], which are interested in using the existing fiber optical infrastructure and FBG sensors for remote monitoring of their objects. For example, with passive FBG sensor solution, where multiple sensors are embedded in different layers of the road pavement, it is possible to monitor road condition during its lifetime. In addition, research of [19] also support the FBG technology topicality in relation to fiber optical sensors in SHM applications and especially highlighting different algorithm tests for detection of tiny wavelength shifts, hence pointing out the importance of an efficient available frequency spectrum and FBG application improvements. Considering that IoT and SHM field develops a closer connection with fiber optical sensors' field [20], therefore it is important to research FBG sensor coexistence with typical fiber optical transmission network infrastructure, starting from combined network architecture and ending with spectrum allocation and minimal spacing between sensors and data transmission channels. In our research, the aim for correct measurement acquisition of physical parameters like temperature and strain and precise detection of FBG sensor central wavelengths or peaks is crucial and can be complicated due to the amplitude fluctuations of FBG's reflected signal peak, as shown in Section 3 of this paper.

\section{Modeling of Combined FBG Sensors and WDM-PON Transmission System Network}

Our simulation setup was developed by using RSOFT OptSim software, where we used measured amplitudefrequency response data of commercial optical temperature sensor, which is a sensitive, ruggedized temperature sensor based on uniform FBG technology (Figure 1). The goal of this modelling is to develop an operating simulation model that provides successful FBG optical temperature sensor network collaboration with 8-channel wavelength division multiplexed passive optical network (WDM-PON). The developed model was further used for observation of temperature effect on sensors' signals (optical signal reflected from deployed FBG sensors) as well as observation and calculation of minimal channel spacing, which led to our proposed peak detection algorithm (Section 3.2). As for the data transmission system, our created model uses a non-return-to-zero on-off keying (NRZ-OOK) modulation scheme. Optical line terminal (OLT) with $10 \mathrm{Gbit} / \mathrm{s}$ transmitters is located in the service provider's side. From structural point of view, we integrated few element configurations based upon our previous research shown in the article [21], where every transmitter includes $10 \mathrm{Gbit} / \mathrm{s}$ pseudorandom binary sequence 
(PRBS) data source, NRZ driver, optical Mach-Zehnder modulator (MZM) with $20 \mathrm{~dB}$ extinction ration and $3 \mathrm{~dB}$ insertion loss, and continuous wave (CW) laser with output power of $+3 \mathrm{dBm}$. For those eight data channels, central frequencies are set as follows: 192.90, 192.95, 193, 193.05, $193.1,193.15,193.2,193.25 \mathrm{THz}$. According to the ITUTG694.1 recommendation [22], data channel spacing is set to $50 \mathrm{GHz}$. Afterwards, all eight of the data transmission channels are then coupled by the optical coupler (MUX) for further transmission in an optical distribution network.

As for the light source, for the sensor network, the broadband light source (BLS) represented by super-luminescent light-emitting diode (SLED) was chosen. The BLS source's optical band from $193.7 \mathrm{THz}$ to $195.3 \mathrm{THz}$ was used for deployment of FBG optical sensors. We experimentally measured the spectrum of SLED source in RTU Fiber Optical Transmission Systems Laboratory and then loaded its amplitude-frequency response data into our simulation model. If we look at the spectral intensity fluctuations in this specific frequency region, we can observe that they are relatively small-less than $0.37 \mathrm{~dB}$ and output power is set to $-9 \mathrm{dBm}$. Our SLED signal, which will be further used as a seed light for optical FBG sensors, is then filtered by an optical bandpass filter and sent to the optical signal coupler (MUX), where it is coupled with 8 data channels from OLT (see Figure 1). In this setup, we use optical circulator for separation of signal transmission directions to separate sensors' (FBGs) reflected signals from transmitted data signals and light source. Influence of the transmission spectrum of a circulator is negligible as circulators' bandwidth is wide enough $(1525-1610 \mathrm{~nm}$ in wavelength or $186.206-196.585 \mathrm{THz}$ in frequency) and the directivity was $>50 \mathrm{~dB}$, and isolation was $>40 \mathrm{~dB}$. In the middle part of the transmission scheme, there is an optical distribution network containing 5 optical FBG temperature sensors and 5 single-mode optical fiber (SMF) spans forming 5 sections with $4 \mathrm{~km}$ distance between each and every sensor. Therefore, the total optical line length is $20 \mathrm{~km}$. The length of the spans was selected to present $4 \mathrm{~km}$, based on the data that such distance is commonly used in Latvia between fiber optical cable cabinets or manholes, where fiber optical closures are placed. In addition, the fact that each sensor is located in the different distances from optical signal interrogation unit allows evaluating the combined system under different scenarios.

As shown in Figure 1, after the last FBG sensor, there is located demultiplexer for separation of data transmission channels, represented by an arrayed waveguide (AWG) and optical network units (ONUs). The received optical sensing signal quality is monitored by a spectrometer, which is connected to a circulator. As an optical receiver, we use PIN photodiodes with a sensitivity of $-17 \mathrm{dBm}$ at reference bit error ratio (BER) $10^{-10}$. PIN output is connected to electrical Bessel low-pass filter with $7.5 \mathrm{GHz} 3 \mathrm{~dB}$ cutoff frequency and afterwards to the electrical scope or BER estimator. This combined scheme provides coexistence of two previously mentioned systems. As we observed in the investigated optical sensor network model, the influence of WDM data transmission channels on sensor signals was negligible, causing only a slight decrease in optical signal to noise ratio of

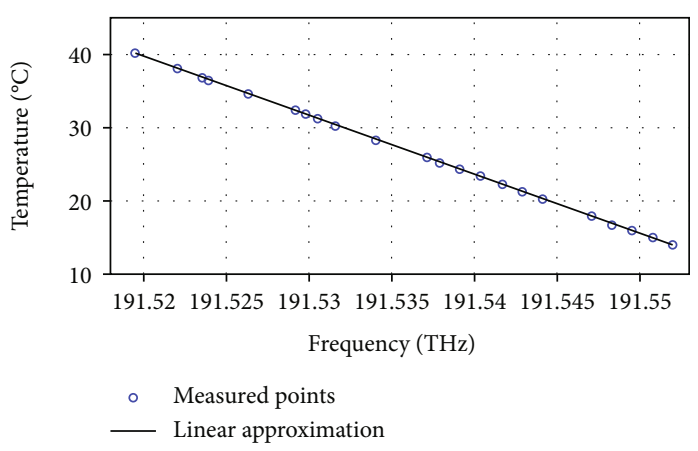

FIgURE 2: Measured experimental data and their linear approximation representing the correlation between temperature and frequency for commercial FBG optical temperature sensor.

received data signals. In other words, by making the overall system more complex (combining both systems by including more devices and elements in total) results in a power loss for optical sensor network. It is also important to remember that with the collaboration of both systems, crosstalk is inevitable, respectively, mutual interference can be observed. Adding to that, signal noise in this situation can be expected, mainly due to each and every simulation schemes' element. However, to make this combined system more resource and spectrum efficient, it is necessary to assess and calculate minimal channel spacing or frequency band between FBG sensor central frequencies (channels) as well as to create an algorithm for precise signal peak detection. Such aspects are further investigated in this article.

\subsection{Research of Minimal Allowable Channel Spacing between} Sensors' Signals. For this research, the precise determination of minimal channel spacing, as well as peak detection using different methods, was important. According to the datasheet of the commercial optical FBG temperature sensor, its calibrated frequency at $+26^{\circ} \mathrm{C}$ is $191.53713 \mathrm{THz}$ or $1565.191 \mathrm{~nm}$ in wavelength and frequency response to temperature change is $1.279 \mathrm{GHz}$ per 1 degree Celsius. The reflectivity of the used FBG temperature sensor is higher than $15 \%$.

In our research, we also compared the theoretical temperature sensor's response from datasheet with our measured one. To perform this, we firstly heated FBG optical sensor to measure a wide variety of FBG's reflected signal central frequencies in the temperature range between $+14^{\circ} \mathrm{C}$ and $+40^{\circ} \mathrm{C}$. The temperature response of the peak frequency of the FBG was measured to be $-1.231 \mathrm{GHz}$ per 1 degree Celsius. The acquired linear equation describing temperature and frequency correlation (response) for the FBG optical temperature sensor is represented in Figure 2.

As one can see, the difference between our experimentally measured FBG response data and manufacturer's provided data is only $3.9 \%$. Therefore, we used the experimentally measured temperature response of the peak frequency of the FBG further in our research. This response value was a decisive factor for the evaluation and analysis of minimal channel spacing between sensor channels.

In Figure 3, you can see the spectrum of the simulated combined system at $0^{\circ} \mathrm{C}$ environment temperature, which 


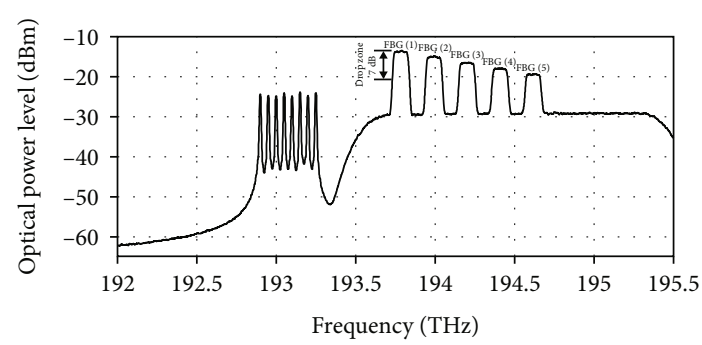

FIGURE 3: Spectrum of simulated combined system with 5 FBG optical sensor reflected peaks and 8 data channels (spectrum obtained by spectrometer located in optical sensor interrogation unit) at $0^{\circ} \mathrm{C}$ environment temperature.

TABle 1: Calculated frequency channel plan of optical FBG temperature sensors.

\begin{tabular}{lc}
\hline FBG sensor's no. & Frequency $(\mathrm{THz})$ \\
\hline 1 & 193.800 \\
2 & 194.008 \\
3 & 194.217 \\
4 & 194.425 \\
5 & 194.633 \\
\hline
\end{tabular}

includes 5 optical FBG sensor channels (FBGs' reflected signals) and 8 data channels, measured by a spectrometer with resolution bandwidth set to $0.07 \mathrm{~nm}$ and located in optical sensor signal interrogation unit. Please pay attention that this is a spectrum of the reflected signal, not the spectrum of transmitted signal; therefore, the 8 data channels are visible and significantly attenuated.

Further, the next FBG parameter was to be estimated, in this case of 5 FBG optical sensors, the average spectral width of sensor signals in the optical power drop zone of $7 \mathrm{~dB}$ (see Figure 3). Here, $7 \mathrm{~dB}$ optical power drop zone applies not only to the first sensor but also to each and every reflected sensor signals' own maximal amplitude.

Power drop zone value was calculated by creating an equation, which is based upon our previous research [23] for the detection of channel spacing between sensor signals in the specific spectrum region:

$$
P_{\text {drop zone }}=10 \cdot \log (n)=10 \cdot \log (5)=7 \mathrm{~dB},
$$

in which $P_{\text {drop zone }}(\mathrm{dB})$ is the optical power drop zone and $n$ is the number of sensors. An equation was created by analysing the optical sensor reflected signals' overlapping in case of different temperature changes for fiber optical sensors that are located close to each other, as well as by evaluating [23] proposed minimal power drop zone diapason value in which the nearby reflected sensor signals should be maintained. With this information, we were able to propose the formula that describes such calculations. This formula was chosen to calculate the worst case scenario-when creating overlapping to one of FBG sensors from all other sensors. According to our measurement results, the average spectral width of sensor peaks in the optical power drop zone of $7 \mathrm{~dB}$ is $109.8278 \mathrm{GHz}$. This value is further used for the determina- tion of minimal frequency channel spacing between adjacent FBG sensors.

We expect that the operating temperature for FBG sensor network will be in the range of $80^{\circ} \mathrm{C}$ (from $-20^{\circ} \mathrm{C}$ to $+60^{\circ} \mathrm{C}$, typical to structural health monitoring applications). By knowing frequency to temperature response as well as spectral width of FBG sensor peaks, we were able to develop our equation to determine theoretical minimal channel spacing (CS) between every FBG optical sensor that was integrated into our system:

$$
\mathrm{CS}=\mathrm{bw}_{\mathrm{avg}}+\left(T_{\mathrm{tot}} \cdot f_{\mathrm{var}}\right),
$$

in which $\mathrm{CS}(\mathrm{GHz})$ is the channel spacing, bw ${ }_{\mathrm{avg}}(\mathrm{GHz})$ is the average spectral width of FBG's reflected signal peak at the optical power drop zone level of $7 \mathrm{~dB}, T_{\text {tot }}\left({ }^{\circ} \mathrm{C}\right)$ is the total expected temperature variation range, and $f_{\text {var }}(\mathrm{GHz})$ is the temperature response of the peak frequency of the FBG for one degree Celsius. After inserting all known variables, the result of minimal channel spacing calculation is as follows:

$$
\begin{aligned}
\mathrm{CS} & =\mathrm{bw}_{\mathrm{avg}}+\left(T_{\text {tot }} \cdot f_{\mathrm{var}}\right) \\
& =109.8278+(80.1 .231) \\
& =208.285 \mathrm{GHz} .
\end{aligned}
$$

The channel plan, based on the abovementioned calculations of FBG sensors, is shown in Table 1.

Accordingly, central frequencies of optical FBG temperature sensors were set in the simulation model as in the table above, starting from the first to the fifth sensor, as it is also seen in Figure 3. We chose such frequencies while considering occupied spectrum by the $10 \mathrm{Gbit} / \mathrm{s}$ downstream data transmission channels to provide stable operation of combined FBG sensors and WDM-PON transmission system network. By stable operation, we mean the case where no overlapping between optical sensors and data transmission channels is observed and it is possible to measure and interrogate both sensor channels and data transmission channels with BER not higher than, for example, $10^{-9}$. These frequencies (Table 1) represent the FBG signal peak frequencies, where peaks have maximal amplitude. However, due to the irregularity of reflected spectra of the FBG sensor, not always the peak point with the highest amplitude is the exact center or central frequency of the peak. Therefore, it is important to develop an algorithm allowing to precisely detecting FBG central frequency, thus reducing the sensor measurement error.

3.2. Development of an Algorithm for Precise FBG Signal Interrogation. If all FBG signals are equally attenuated (e.g., located in one physical place), deployed relatively apart from each other in the spectrum and FBG has smooth amplitudefrequency response curve, then interrogation of FBG signals is not a hard task. Nevertheless, there are some difficulties in real applications, where FBG optical sensors are located in different physical locations; therefore, each FBG peak experiences different amounts of attenuation. For example, in situations when there are multiple FBG sensors connected 


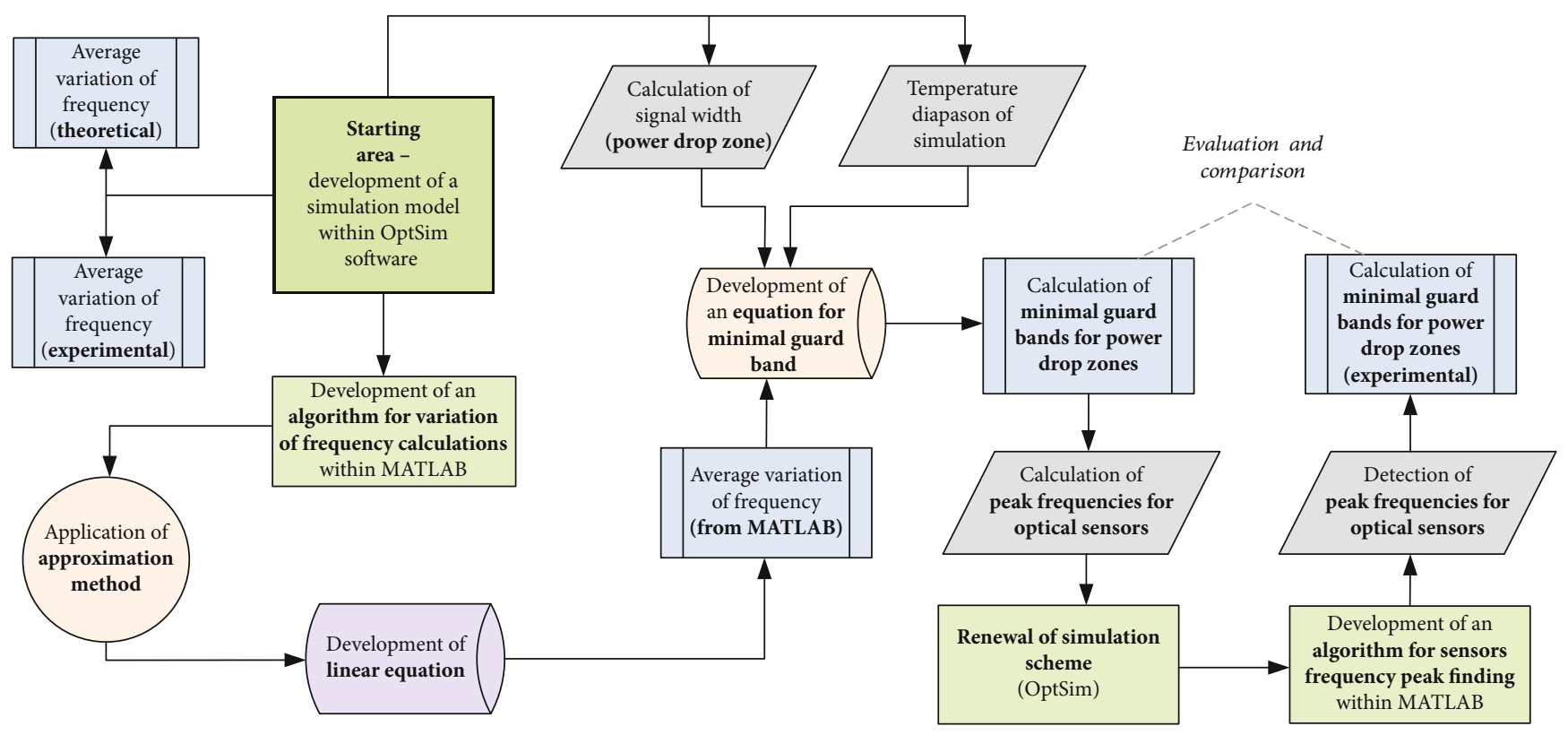

FIGURE 4: Flowchart of the algorithm development for precise detection of the exact center of the signal's peak (central frequency).

in series on one optical fiber and they are located in different distances between each other, a different amount of attenuation (decrease in optical power) on each reflected sensor peak can be observed. It generally leads to the situations where some reflected sensor signal peaks can be very attenuated if compared to the signal peaks of the sensors, which are physically connected closer to the interrogator. Not to forget that light is passing through optical fiber twice-first through optical sensors and then reflected back through the circulator. In that case, it is important to detect the precise center of the reflected sensor signal peaks for systems' optimization, as well as efficient preservation of the available frequency spectrum. Accordingly, if the sensor is located farther away from the interrogation unit, then its signal is more attenuated, as it can be seen in Figure 3.

Thereby, authors offer a precise peak detection solution created within MATLAB software. Our work structure and sensors' signal processing order is visualized in the flowchart (see Figure 3). This figure represents our research process starting from the creation of a simulation model and ending with the creation of an algorithm (MATLAB code) for the finding of precise sensors' peak central frequencies.

As shown in Figure 4, based on the measured temperature response of the peak frequency of the FBG and creation of minimal channel spacing equation, it is possible to evaluate minimal FBG channel spacing what was also one of the main objectives during this research. Subsequently, we investigated peak central frequency calculations for sensor signals, and by updating our OptSim simulation model with new adjustments, we were able to create a new algorithm (written as MATLAB code) for determination of the exact center of the sensor signal's peak that was yet another objective of this research. Once that it was completed, it was possible to compare traditional approach, where the peak central frequency is the peak's point with the highest intensity (standard automatic peak detection) against our pro- posed algorithm, where the peak central frequency is the exact center of the peak.

In order to determine precise channel spacing between FBG signals, it is important to locate an exact center of each signal peak and vice versa. It needs to be made clear that not always the highest value in a peak region is its center. In this case, all the commonly used standard algorithms (represented as " $x$ " in Figure 5) of automatic peak finding, regardless of the MATLAB algorithm typically used, do not achieve the needed result, as shown in Figure 5.

As it is shown in Figure 5, it is not an easy task to detect the exact center of the FBG's reflected signal's peak due to its irregularity. To solve this problem, we created an algorithm within MATLAB software where we imported data about sensor signals from OptSim simulation scheme discussed in this article. Our method and approach are similar to the one widely used for measurement of pulse width-wellknown full width at half maximum (FWHM) method. To detect the exact center of each FBG sensors' peak, we based our calculations upon relative peak power level that was equal to $90 \%$ from its maximum. When the algorithm had detected $90 \%$ power level, it started locating spectrum values on both sides-left and right. Once it had acquired such values, it mathematically summarized both values and divided by two. Then, from this point at the $90 \%$ power level, algorithm started finding a spectrum point that is located upwards till it reached the exact point, which was our desired exact signals' peak middle point. With such a method being used, we improved our FBG signal interrogator accuracy and excluded the wrong detection of signal peaks due to power fluctuations and irregularity of the frequency spectrum.

Once we composed this algorithm, it provided us the ability to process spectrum data of each sensor and detect the exact center frequency of each sensor's reflected signal (see Figure 6 and Table 2). 


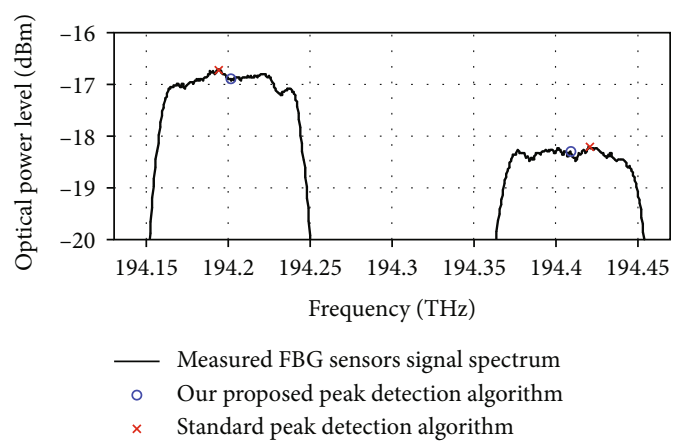

Figure 5: Comparison between standard automatic peak detection algorithm, based on the highest value in the peak region, and our proposed algorithm, which detects the exact center of the peak for $3^{\text {rd }}$ and $4^{\text {th }}$ FBG sensors.

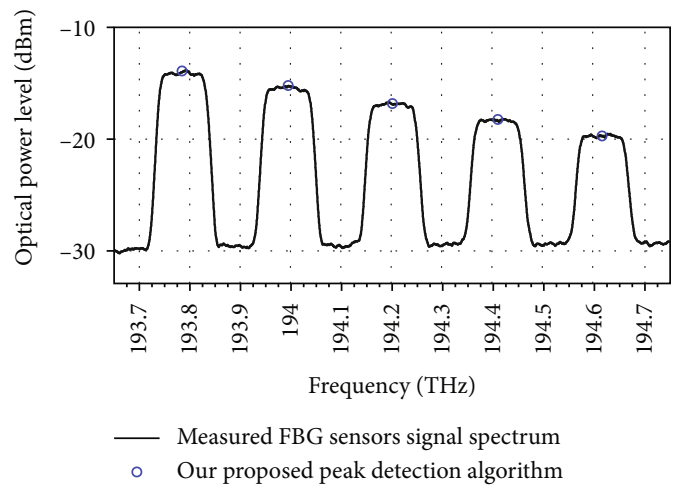

FIGURE 6: Reflected signal spectrum of 5 simulated FBG sensors with precisely detected center peak frequencies by using the proposed algorithm.

TABLE 2: Calculated and detected FBG optical sensor central signal frequencies using both methods.

\begin{tabular}{|c|c|c|c|}
\hline \multirow[b]{2}{*}{$\begin{array}{l}\text { FBG } \\
\text { sensor's } \\
\text { no. }\end{array}$} & \multicolumn{2}{|c|}{$\begin{array}{l}\text { Central peak frequency }(\mathrm{THz}) \\
\text { obtained by }\end{array}$} & \multirow[b]{2}{*}{$\begin{array}{c}\text { Difference } \\
(\mathrm{GHz})\end{array}$} \\
\hline & $\begin{array}{l}\text { Calculated } \\
\text { central } \\
\text { frequencies }\end{array}$ & $\begin{array}{l}\text { Measured with } \\
\text { our proposed peak } \\
\text { detection } \\
\text { algorithm }\end{array}$ & \\
\hline 1 & 193.800 & 193.785 & 15.166 \\
\hline 2 & 194.008 & 193.994 & 14.084 \\
\hline 3 & 194.217 & 194.201 & 15.385 \\
\hline 4 & 194.425 & 194.409 & 15.642 \\
\hline 5 & 194.633 & 194.616 & 17.322 \\
\hline $\begin{array}{l}\text { Channel } \\
\text { spacing } \\
(\mathrm{GHz})\end{array}$ & 208.285 & 207.746 & 0.539 \\
\hline
\end{tabular}

Knowing that FBG channel spacing is estimated as a difference between two adjacent FBG signal peak centers and that our newly acquired peak center frequency values differ from values obtained by calculated FBG's central frequencies (as shown in Table 1), it was understandable that the channel spacing will differ as well. Therefore, we summarized the newly detected central frequencies of FBGs's peaks in Table 2, as well as compared them to previously obtained values by calculated central FBG's frequencies. From these results, channel spacing values can also be determined and compared to each other.

As it is possible to observe from Table 2, there is a difference between frequency values $(\mathrm{GHz})$. This number is representing the difference in error between both used algorithms.

From our results, it is clear that such a peak detection algorithm can be integrated into FBG optical sensor interrogation units to precisely detect the exact center of each FBG signal's peak.

\section{Research of Concept for the Coexistence of Single Light Source Fed Fiber Optical Data Transmission System with Embedded FBG Sensor Network over Shared Optical Fiber}

One of the appealing ideas in the matter of optical sensor networks and data transmission systems is by unifying their input light sources. In this case, the spectrum-sliced wavelength division multiplexing (SS-WDM) technology that is realized with amplified spontaneous emission (ASE) source might be considered to achieve such a goal. SS-WDM was chosen for our further study due to its advantages also discussed in the article [24], for instance, cost-efficient solution that can be acquired by its ability to compose optical elements and electronics in one central office allowing network architecture simplification specifically for optical transmitter side.

We developed a simulation model and an experimental model of a spectrum-sliced WDM transmission system, where one broadband ASE source was shared by the optical transmission system and sensor network at the same time (see Figures 7 and 8). Differently, from other related studies in this field, we focused our goal on achieving error-free transmission system model that provides reliable output for both data transmission and optical sensor channels. Adding to that, our initial research in this matter uses the data transmission rate of maximum $1.5 \mathrm{Gbit} / \mathrm{s}$ per channel, which was limited by the characteristics of the light source, as described further.

4.1. Description of Realized Spectrum-Sliced Transmission System Simulation Model with Embedded FBG Sensor. Another one simulation carried out within OptSim software was aimed for a better understanding of the influence of the FBG optical sensor system on the data transmission system which was unified together with the optical sensor system. Figure 7 shows the created simulation model that has 3 main parts-central office (CO), optical distribution network (ODN), and optical network terminal (ONT). In central $\mathrm{CO}$ part, here for the BLS source, we chose amplified spontaneous emission (ASE) source. The ASE source's optical band from $191.75 \mathrm{THz}$ to $195.8 \mathrm{THz}$ was used to provide operation of FBG optical sensor. We experimentally measured the spectrum of the ASE source and then loaded its spectral characteristics into our simulation model. Please see the measured spectrum of ASE source in Figure 9. 


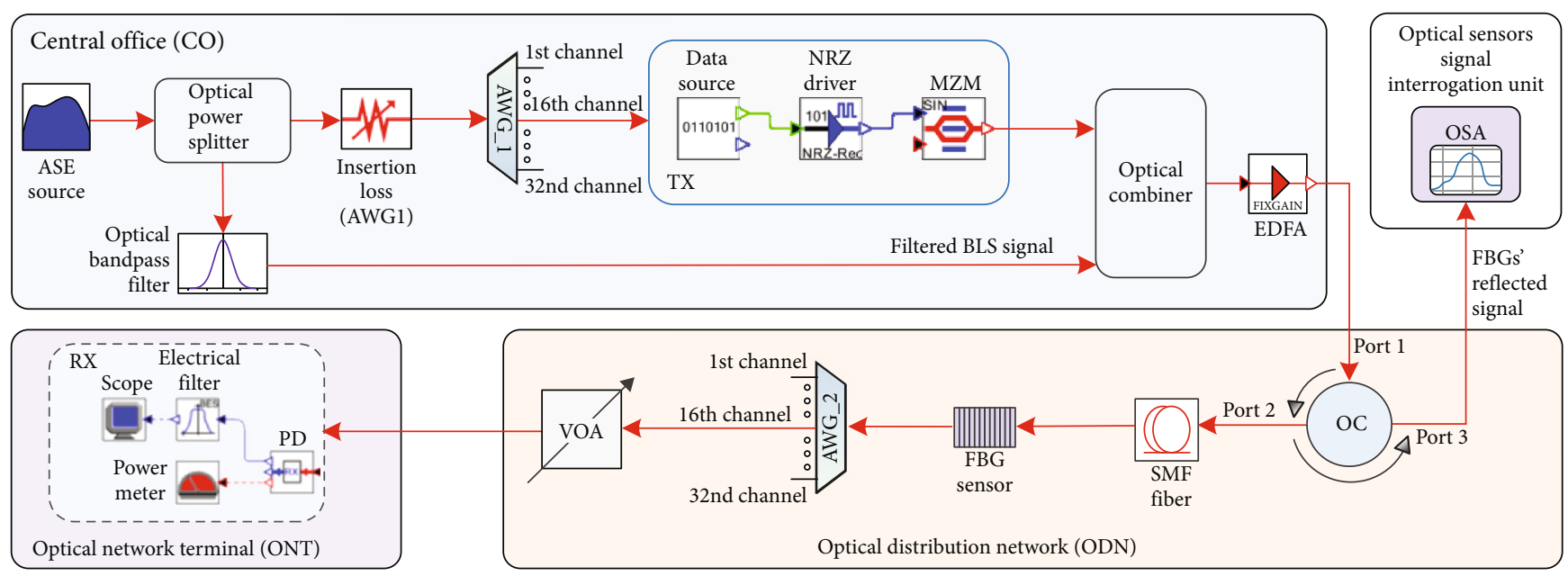

FIGURE 7: The simulation model of $1.5 \mathrm{Gbit} / \mathrm{s}$ spectrum-sliced transmission system with embedded FBG sensor.

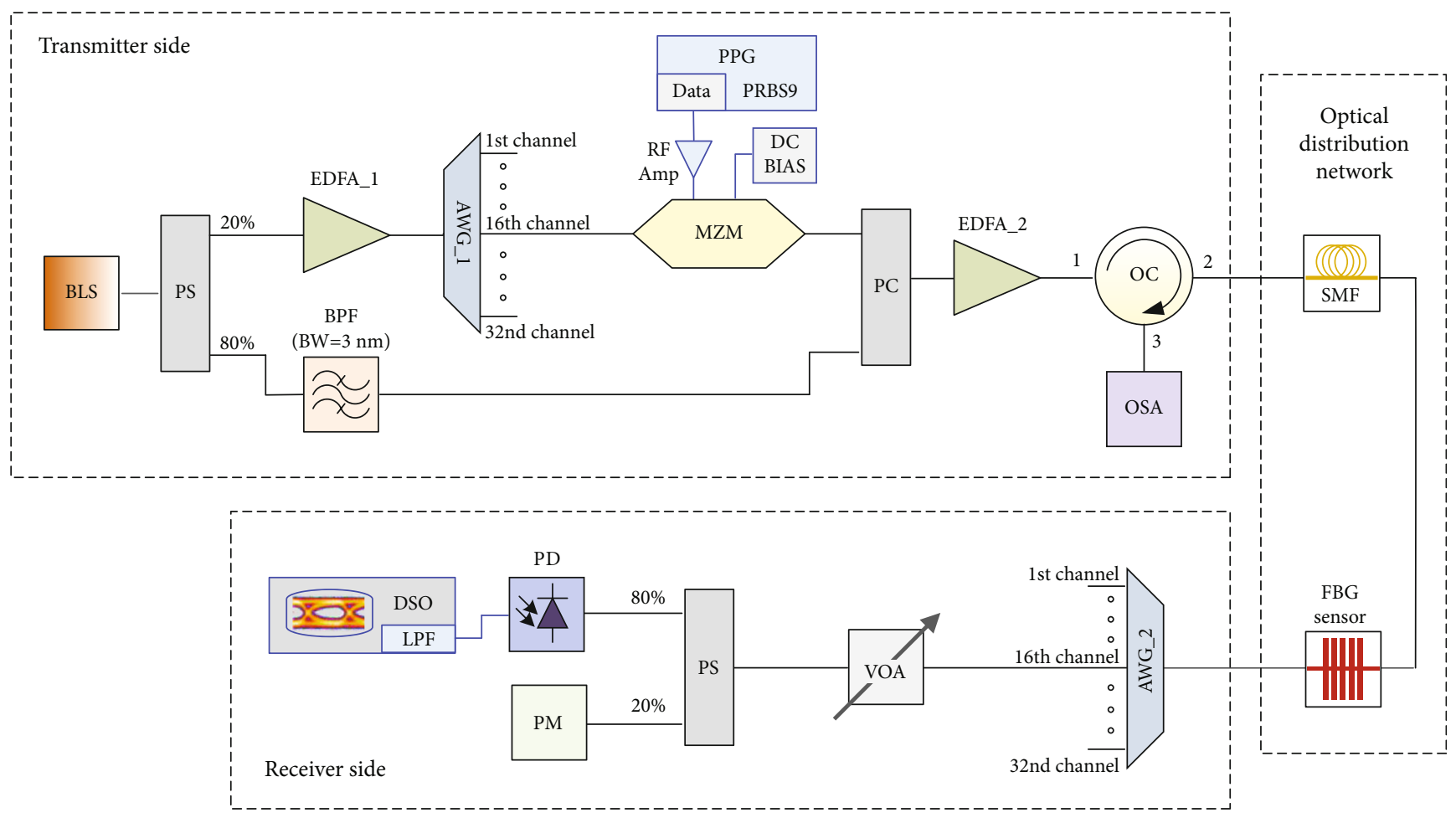

FIGURE 8: Experimental system of spectrum-sliced WDM fiber optical transmission system with embedded FBG sensing system fed by a single shared broadband light source.

Further, optical power splitter was used for dividing the optical signal into two parts (with 50:50 power division ratio). One of the signal parts was used for data transmission channel needs and the other one for FBG optical sensors' spectrum allocation. 32-channel AWG was chosen for the separation of data transmission channels. The central frequency for data transmission channel is set to $193.1 \mathrm{THz}$ or $1552.52 \mathrm{~nm}$, according to ITU-TG.694.1 frequency grid. From Figure 7, it is possible to observe the structure of every transmitter (Tx), where they consist of data source, nonreturn-to-zero (NRZ) driver, and Mach-Zehnder modulator (MZM) with an extinction ratio of $26 \mathrm{~dB}$. The other part of the signal (50\%) is filtered through an optical bandpass filter (OBF). Here, the OBF with $1 \mathrm{THz} 3 \mathrm{~dB}$ bandwidth is used to avoid overlapping of modulated data channels and the BLS source spectrum intended for the operation of FBG sensors. Then, both signals are coupled by using optical Y type (50\%:50\%) coupler. Afterwards, coupled optical signal is amplified by EDFA with $20.5 \mathrm{~dB}$ fixed gain (output power up to $22 \mathrm{dBm}$ ).

Next, in the optical distribution network (ODN), to provide the ability to observe FBG optical sensor (with optical spectrum analyzer (OSA)), the optical circulator is chosen for the optical sensor to separate combined transmitted 


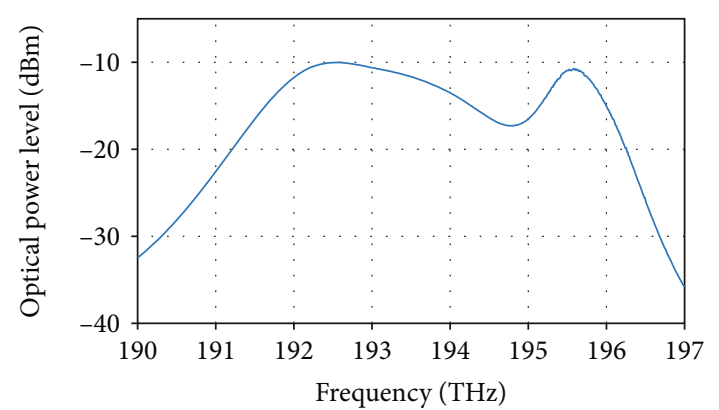

Figure 9: Measured optical spectrum of broadband ASE light source.

signal from FBGs' sensor reflected signals. Furthermore, the data transmission channel signal is carried by $20 \mathrm{~km}$ long SMF fiber line through FBG sensor and variable $3 \mathrm{~dB}$ optical attenuator (VOA) to AWG 2, where 16th data transmission channel is observed in optical network terminal (ONT).

ONT here consists of receiver part-high-speed pin photodiode with $-18 \mathrm{dBm}$ sensitivity $\left(10^{-10} \mathrm{BER}\right)$, electrical Bessel low-pass filter with $1.25 \mathrm{GHz} 3 \mathrm{~dB}$ bandwidth, electrical scope, and optical power meter.

Here, multiple scenarios for one channel were tested. Data transmission speed is set to $1.5 \mathrm{Gbit} / \mathrm{s}$. Then, signal quality-BER difference (BER correlation diagrams) with and without FBG optical sensor-is measured while the data transmission line is $20 \mathrm{~km}$ long. In Figure $10(\mathrm{~b})$, it is possible to observe BER versus average received optical power of $1.5 \mathrm{Gbit} / \mathrm{s}$ signals after transmission over $20 \mathrm{~km}$ long SMF fiber. Afterwards, the same configuration is applied, yet $20 \mathrm{~km}$ long data transmission line is changed to back-to-back (B2B) condition (without data transmission line). Figure 10(a) shows the BER correlation diagrams for B2B transmission.

From measured results (see Figure 10), we calculated that for system with $\mathrm{B} 2 \mathrm{~B}$ and $20 \mathrm{~km}$ long SMF fiber, the power penalty, in case of both system collaborations, is approximately 0.5 and $0.2 \mathrm{~dB}$ at the forward error correction (FEC) level of $2.3 \times 10^{-3}$, if compared to the optical transmission system without embedded FBG sensor. The power penalty (system with FBG sensor) for $20 \mathrm{~km}$ optical signal transmission compared to $\mathrm{B} 2 \mathrm{~B}$ measurement at FEC level of BER = $2.3 \times 10^{-3}$ is approximately $0.7 \mathrm{~dB}$, which can be characterized as negligible.

4.2. Description of Developed Experimental Combined Network Setup. To prove the concept of the coexistence of fiber optical transmission system with embedded FBG sensor network over one shared optical fiber, we realized the experimental fiber optical system setup as shown in Figure 8.

The key point in this system is that only one shared broadband light source (BLS) is used for data transmission and sensing channels. It is important to highlight that for simulation (Section 3) and experimental (Section 4) purposes, the same FBG optical sensor's spectral response curve has been used.

Realized WDM data transmission system is based on the spectrum slicing approach of BLS light source, namely, broadband ASE light source. As an alternative to ASE, the light-emitting diodes (LED) or super-luminescent emitting diodes (SLED), which typically have higher output power, also can be used for the realization of spectrum-sliced multichannel transmission system. However, in our setup, we used ASE due to its higher average optical output power $(+7 \mathrm{dBm})$, if compared to available SLED $(+4 \mathrm{dBm})$. Please see the measured spectrum of ASE source in Figure 9.

The bitrate of the investigated data transmission system is chosen to be $1.5 \mathrm{Gbit} / \mathrm{s}$ per channel and also $1.25 \mathrm{Gbit} / \mathrm{s}$ to test lower transmission speeds. Transmission bitrate in such a type spectrum-sliced optical communication systems is limited by the excess intensity noise (EIN) evaluated in the articles $[25,26]$, where it is discussed that particular noise is created by the spontaneous-spontaneous beating between different wavelength components of the spectrum-sliced light. Moreover, articles [27, 28] propose that the intensity noise can be suppressed by gain saturated semiconductor optical amplifier (SOA), which amplifies incoming carrier spectral slice, as well as suppresses EIN, which rises from the spontaneous-spontaneous beating between different wavelength components of the spectrally sliced incoherent broadband ASE light source. However, it adds extra complexity to the optical transmission system.

The capacity of experimental system setup is up to 32 spectrum-sliced channels for data transmission, which are limited by the bandwidth of BLS source, optical signal power, and the number of output channels of arrayed waveguide grating (AWG) used for slicing operation. However, for the proof of principle, we set-up and investigated only one separate data channel (only one AWG slice for further data transmission was used) and one FBG sensing channel in the same model, where all system is feed by one shared BLS source.

In transmitter side, an optical signal from BLS source is split into two arms by a $20 / 80$ power splitter, where the $20 \%$ output port was connected to the input of erbiumdoped fiber amplifier (EDFA) and $80 \%$ output port to an optical band pass (OBP) filter. This splitting ratio of power splitter (PS) is chosen intentionally to provide sufficient optical signal power for FBG sensing purposes. OBP was used to provide dedicated ASE spectrum region for experimentally used fiber Bragg grating (FBG) temperature sensor and to ensure that this signal will not overlap with data channels. The $20 \%$ PS output port with $0 \mathrm{dBm}$ average optical signal power is fed to first EDFA (EDFA_1) and amplified up to $18.1 \mathrm{dBm}$. This was done to compensate relatively high insertion loss (loss was $8.6 \mathrm{~dB}$ ) of $10 \mathrm{GHz}$ Mach-Zehnder modulator (MZM) and AWG. The high loss in MZM is explained in [29] where it is stated that MZM is polarization-sensitive and ASE by its nature is randomly polarized chaotic light, therefore introducing excess loss.

For slicing of BLS light source and demultiplexing of data transmission channels, we used two AWGs with $100 \mathrm{GHz}$ channel spacing each. The first AWG (in the setup shown as $A W G_{-} 1$ ) is flat-top type with $54 \mathrm{GHz} 3 \mathrm{~dB}$ and $132 \mathrm{GHz} 20 \mathrm{~dB}$ bandwidth. Second AWG (AWG_2), which is used for demultiplexing of data channels, is Gaussiantype with $77.5 \mathrm{GHz} 3 \mathrm{~dB}$ and $145 \mathrm{GHz} 20 \mathrm{~dB}$ bandwidth. First AWG (AWG_1) introduced optical signal loss equal 


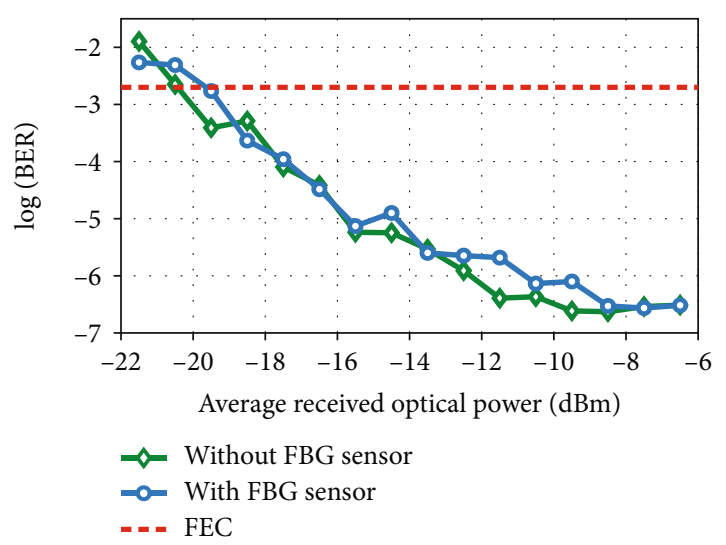

(a)

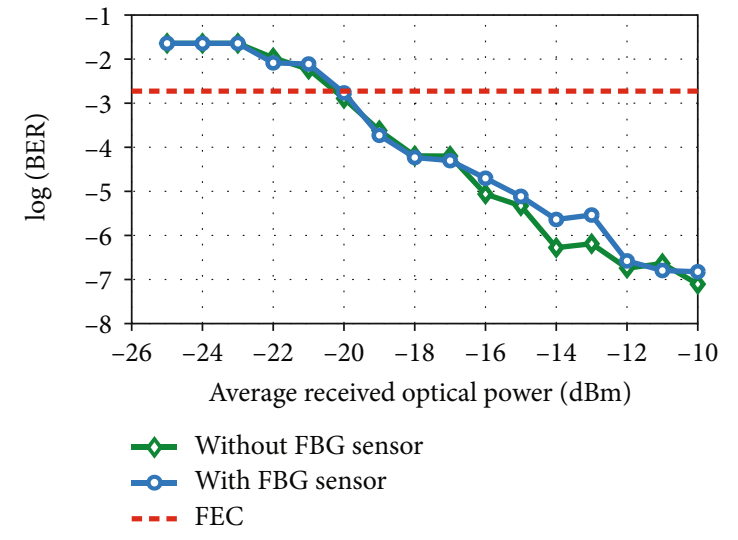

(b)

Figure 10: BER versus average received optical power of $1.5 \mathrm{Gbit} / \mathrm{s}$ spectrum-sliced data signals for (a) B2B transmission and (b) after transmission over $20 \mathrm{~km}$ long SMF fiber.

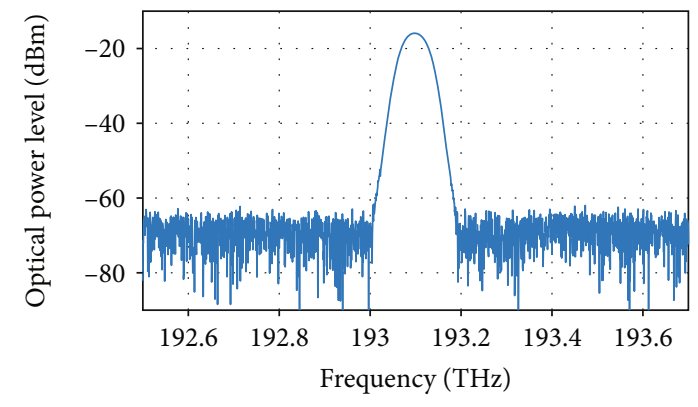

FIGURE 11: Optical spectrum of modulated $1.5 \mathrm{Gbit} / \mathrm{s}$ NRZ-OOK spectral slice.

to $23.2 \mathrm{~dB}$ that is formed from insertion loss of AWG unit ( $4 \mathrm{~dB}$ at $1552.52 \mathrm{~nm}$ wavelength) and loss due to the slicing operation, where the relatively narrow carrier spectral slice is spectrally cut out from wide BLS source spectrum. For further modulation of the carrier, we used $16^{\text {th }}$ output channel of AWG unit with a central frequency of $193.1 \mathrm{THz}$ or $1552.52 \mathrm{~nm}$, according to ITU-TG.694.1 frequency plan. The $16^{\text {th }}$ output channel of AWG produces optical spectral slice with an average power of $-5.1 \mathrm{dBm}$, which is further launched into $10 \mathrm{GHz} \mathrm{LiNbO}_{3}$ intensity modulator biased at the quadrature point of $\mathrm{DC}_{\text {bias }}=6.6 \mathrm{~V}$. Optical spectrum of the second AWG filtered and $1.5 \mathrm{Gbit} / \mathrm{s}$ NRZ-OOKmodulated spectral slice is shown in Figure 11.

Up to $12.5 \mathrm{GHz}$ pulse pattern generator (PPG) is used to generate $2^{9}-1$ long pseudorandom bit sequence (PRBS) with bitrates of $1.25 \mathrm{Gbit} / \mathrm{s}$ and $1.5 \mathrm{Gbit} / \mathrm{s}$, respectively. Electrical signal adopted non-return-to-zero (NRZ) coding scheme with peak-to-peak voltage $\left(\mathrm{V}_{\mathrm{pp}}\right)$ of 0.7 volts. The output signal of the PPG is amplified by $25 \mathrm{GHz}$ broadband $\mathrm{RF}$ amplifier with $17 \mathrm{~dB}$ gain, forming electrical NRZ signal with $5 \mathrm{~V}_{\mathrm{pp}}$ swing to drive the MZM modulator and obtain the maximum extension ratio of a modulated optical signal evaluated in [30].

Afterwards, MZM-modulated signal and BPF's filtered ASE signal are coupled by Y-type (50/50) power coupler (PC). Afterwards, combined optical signal is amplified up

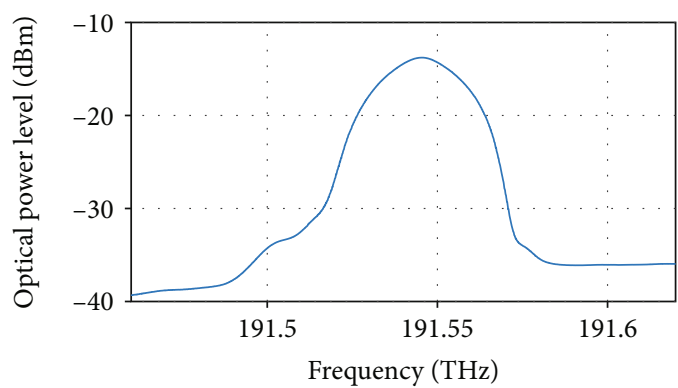

FIGURE 12: Measured spectrum of FBG temperature sensor's reflected signal.

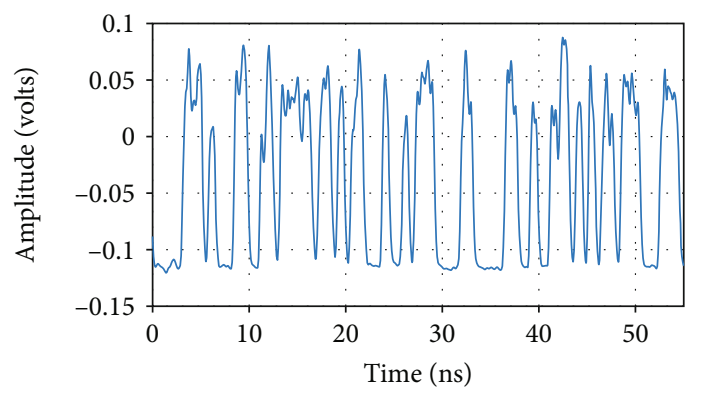

FIGURE 13: Captured waveform of the received $1.5 \mathrm{Gbit} / \mathrm{s}$ signal after $20 \mathrm{~km}$ SMF transmission.

to $16 \mathrm{dBm}$ by second EDFA (EDFA_2). The output of the second EDFA is connected to optical circulator (OC), which is used for separation of the data transmission signal (ports 1 to 2) and FBG reflected signal (ports 2 to 3 ). Here, the high precision optical spectrum analyzer (OSA) is used for interrogation of FBG reflected the optical signal. The OC's output optical signal is launched into the optical distribution network (ODN) represented by an ITU G.652 single-mode optical fiber (SMF) and FBG temperature sensor with a central wavelength of $\lambda=1565.124 \mathrm{~nm}(191.5455 \mathrm{THz})$ corresponding to the temperature of +19.44 degrees Celsius. The central wavelength of the FBG sensor was measured from a reflected signal spectrum shown in Figure 12. The FBG sensor, 


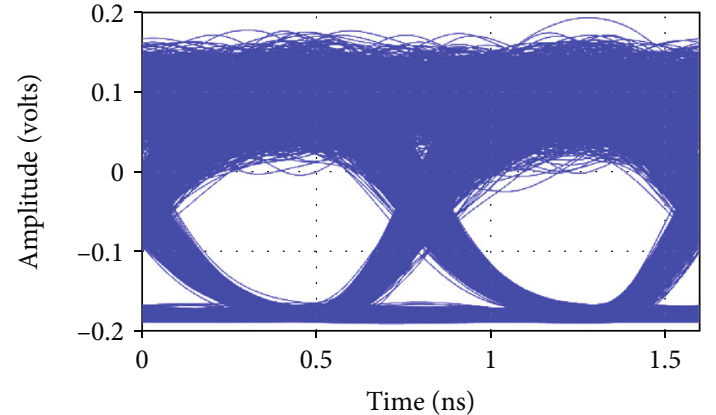

(a)

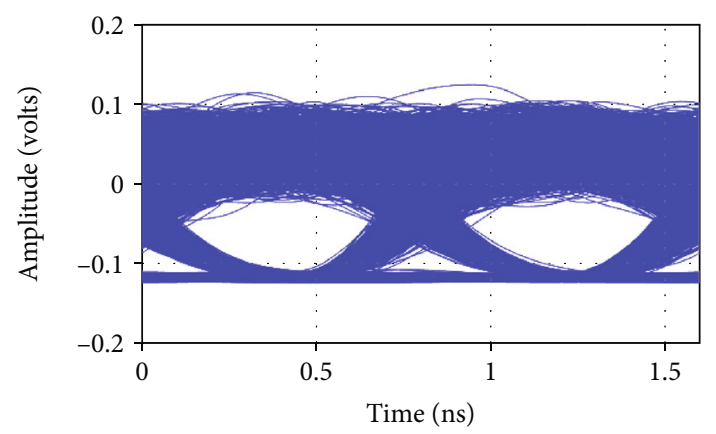

(c)

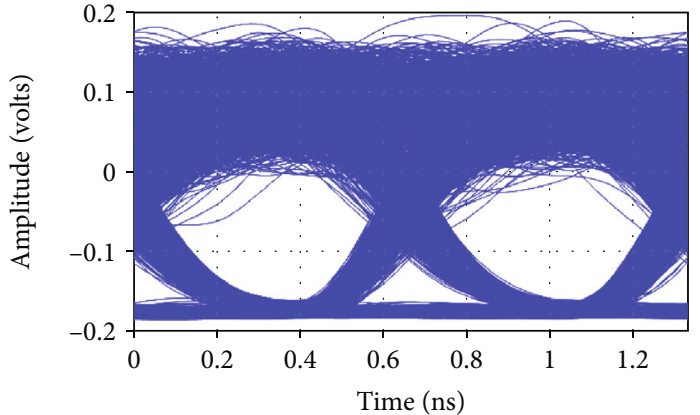

(b)

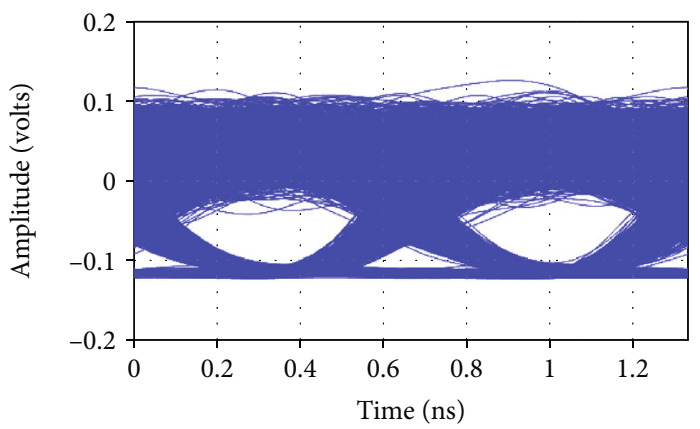

(d)

Figure 14: Eye diagrams of received (a) $1.25 \mathrm{Gbit} / \mathrm{s}$ B2B signal, (b) $1.5 \mathrm{Gbit} / \mathrm{s}$ B2B signal, (c) $1.25 \mathrm{Gbit} / \mathrm{s}$ signal after $20 \mathrm{~km}$ transmission, and (d) $1.5 \mathrm{Gbit} / \mathrm{s}$ signal after $20 \mathrm{~km}$ transmission over SMF fiber.

according to its data sheet, was calibrated to $\lambda=1565.191 \mathrm{~nm}$ (191.537 THz) corresponding to +26 degrees Celsius.

In receiver side, the second AWG (AWG_2) is performing demultiplexing operation of data channels. Here, the $16^{\text {th }}$ output channel of AWG is connected to a linear variable optical attenuator (VOA) with $1.5 \mathrm{~dB}$ insertion loss at the used wavelength. The VOA is used to emulate different loss budgets in the ODN, therefore enabling measurement of BER versus received average optical power. The output of the VOA is connected to $20 / 80$ power splitter, where the $20 \%$ output port is connected to the monitoring power meter (PM) and $80 \%$ output port to a photodiode (PD) with $10 \mathrm{GHz}$ bandwidth. The PD converts the optical signal into an electrical signal, which is captured by a digital storage oscilloscope (DSO) with $33 \mathrm{GHz}$ bandwidth and $80 \mathrm{GSa} / \mathrm{s}$ sampling rate. The bandwidth of DSO is limited down to $0.9 \mathrm{GHz}$ (for $1.25 \mathrm{Gbit} / \mathrm{s}$ bitrate) and $1.05 \mathrm{GHz}$ (for $1.5 \mathrm{Gbit} / \mathrm{s}$ ) by applying 4 th order Bessel-Thomson low-pass filter response for noise reduction purpose. The waveform of received $1.5 \mathrm{Gbit} / \mathrm{s}$ NRZ-OOK-modulated signal after $20 \mathrm{~km}$ transmission is shown in Figure 13. The amplitude fluctuations in the logical " 1 " level are well observed due to the noise-like nature of ASE source.

4.3. Performance Analysis of Experimental Setup. As one can see in Figures 14(a) and 14(c), after 1.25 Gbit/s B2B transmission, the eye diagram of the received optical signal is wide open and measured BER $=4.6 \times 10^{-16}$ but after transmission over $20 \mathrm{~km}$ long ITU-TG.652 SMF fiber span, the BER increases up to BER $=1.3 \times 10^{-9}$.
As one can see in Figures 14(b) and 14(d), an increase of bitrate from 1.25 to $1.5 \mathrm{Gbit} / \mathrm{s}$ leads to the decrease of received signal quality. Numerically, the BER value in the case without transmission optical fiber (B2B) with a bitrate of $1.5 \mathrm{Gbit} / \mathrm{s}$ received optical signals' BER was $9.7 \times 10^{-12}$. However, after $20 \mathrm{~km}$ transmission over $20 \mathrm{~km}$ long SMF fiber span, it increased up to $B E R=6.1 \times 10^{-7}$. It must be taken into account that during the data transmission, the transmitted signal has been affected by parallel transmitted FBG sensor seed signal (coming from BPF). We observed that the impact of this sensor's seed light on the received signal quality was negligible, as the spectrum regions of FBG sensor and data channels do not overlap and there is provided sufficient spectral spacing between them.

From obtained results (see Figure 15), we calculated that for the bitrate of $1.5 \mathrm{Gbit} / \mathrm{s}$, the power penalty for $20 \mathrm{~km}$ signal transmission compared to back-to-back (B2B) measurement at forward error correction (FEC) level of $\mathrm{BER}=2.3 \times 10^{-3}$ is approximately $1.5 \mathrm{~dB}$.

This power penalty is introduced mainly due to the noise-like nature of broadband ASE light source and dispersion. As one can see in Figures 15(a) and 15(b), BER performance below the $7 \%$ overhead FEC limit of $2 \times 10^{-3}$ is achieved in all transmission cases with 1.25 and $1.5 \mathrm{Gbit} / \mathrm{s}$ bitrates. Consequently, an error-free transmission is possible and the coexistence of data and sensor network in one system is experimentally demonstrated.

As it is shown, due to sensor system prevalence in modern days and with successful system integration, the overall benefit can be obtained, mainly highlighting the reduction 


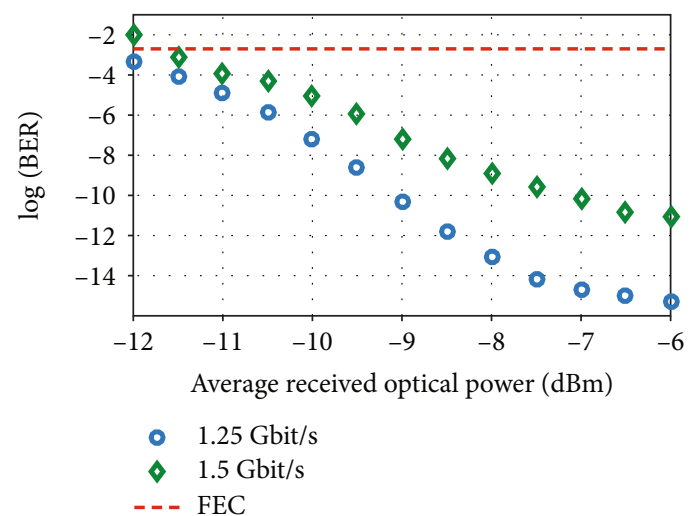

(a)

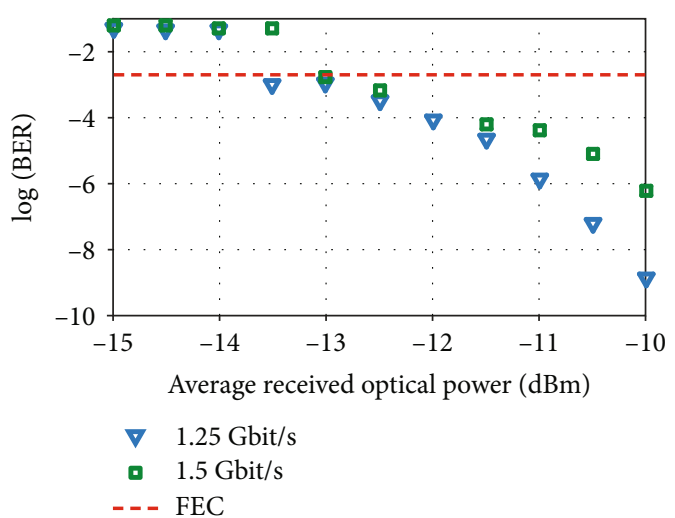

(b)

FIGURE 15: BER versus average received optical power of $1.25 \mathrm{Gbit} / \mathrm{s}$ and $1.5 \mathrm{Gbit} / \mathrm{s}$ signals for (a) B2B transmission and (b) after transmission over $20 \mathrm{~km}$ long SMF fiber span.

of network structure complexity and their coexistence with deployed fiber optical infrastructure. From this, it is clear that even further studies can be planned in order to test higher transmission speeds as well as integrating more system elements, e.g., optical sensors and data channels.

\section{Conclusions}

Market trends show that industry is in constant demand for fiber optical sensors in a wide variety of applications. Looking from a financial point of view, the annual growth in the market for such technology is increasing steadily every year. As one of the fields, where fiber optical sensors are needed and so will be in the future, is the Internet of Things (IoT) and especially structural health monitoring (SHM) applications, e.g., monitoring of the technical condition of buildings, bridges, and roads.

In this paper, we show a successful combination of 5 FBG optical sensor networks with 8-channel NRZ-OOKmodulated $10 \mathrm{Gbit} / \mathrm{s}$ fiber optical data transmission system. During this research, we offered the equation for calculation of minimal channel spacing, which allows calculating the minimal frequency band between adjacent optical FBG sensors to provide that their reflected signals will not overlap in spectrum region. Obtained results showed that, in our case, the frequency channel spacing between two adjacent deployed FBG temperature sensors should be at least around $208 \mathrm{GHz}$. Traditionally used peak detection algorithms define that the peak central frequency is the peak's point with the highest intensity. However, not always, the highest point is the peak center due to power fluctuations and irregularity of FBG's reflected signal frequency spectrum. Therefore, in this paper, we proposed and validated the algorithm for precise detection of signal peak's central frequency. This algorithm has direct application in FBG signal interrogation solutions as well as in other applications in a wide variety of fields.

We have experimentally demonstrated the coexistence of fiber optical transmission system with an FBG sensor network over one shared optical fiber and unified broadband light source for both systems. Error-free transmission has been demonstrated over different bitrates $(1.25 \mathrm{Gbit} / \mathrm{s}$ and $1.5 \mathrm{Gbit} / \mathrm{s})$ over $20 \mathrm{~km}$ long ITU G.652 single-mode optical fiber (SMF), in the same time providing successful operation of FBG temperature sensor. Therefore, the successful operation of multifunctional fiber optical data transmission and optical sensing solution has been demonstrated. Authors believe that the more FBG sensor technologies will develop, the bigger will be the need for research on the coexistence of data transmission and sensing systems in a unified system operating over one shared optical fiber.

\section{Data Availability}

The data used to support the findings of this study are available from the second author upon request.

\section{Conflicts of Interest}

The authors declare that there is no conflict of interest regarding the publication of this paper.

\section{Acknowledgments}

This work has been supported by the European Regional Development Fund project no. 1.1.1.1/16/A/072.

\section{References}

[1] F. Bortolotti, K. Morais Sousa, and J. C. Cardozo da Silva, "Packaging, characterization and calibration of the Bragg grating temperature sensors," in Proceedings of the MOMAG 2012-15 SBMO-Brazilian Microwaves and Optoelectronics Symposium and the 10 CBMag Brazilian Conference on Electromagnetism, pp. 1-5, João Pessoa, Paraíba, Brasil, August 2012.

[2] C. E. Campanella, A. Cuccovillo, C. Campanella, A. Yurt, and V. M. N. Passaro, "Fibre Bragg grating based strain sensors: review of technology and applications," Sensors, vol. 18, no. 9, p. 3115, 2018.

[3] T. Becker, O. Ziemann, R. Engelbrecht, and B. Schmauss, "Optical strain measurement with step-index polymer optical 
fiber based on the phase measurement of an intensitymodulated signal," Sensors, vol. 18, no. 7, p. 2319, 2018.

[4] G. Laffont, R. Cotillard, N. Roussel, R. Desmarchelier, and S. Rougeault, "Temperature resistant fiber Bragg gratings for on-line and structural health monitoring of the nextgeneration of nuclear reactors," Sensors, vol. 18, no. 6, p. 2018, 1791.

[5] K. Bremer, L. S. M. Alwis, F. Weigand et al., "Evaluating the performance of functionalized carbon structures with integrated optical fiber sensors under practical conditions," Sensors, vol. 18, no. 11, p. 3923, 2018.

[6] B. W. Jo, R. M. A. Khan, Y. S. Lee, J. H. Jo, and N. Saleem, "A fiber Bragg grating-based condition monitoring and early damage detection system for the structural safety of underground coal mines using the Internet of things," Journal of Sensors, vol. 2018, Article ID 9301873, 16 pages, 2018.

[7] A. Leal-Junior, J. Casas, C. Marques, M. J. Pontes, and A. Frizera, "Application of additive layer manufacturing technique on the development of high sensitive fiber Bragg grating temperature sensors," Sensors, vol. 18, no. 12, p. 4120, 2018.

[8] D. Qiu, T. Wang, Q. Ye et al., “A deformation prediction approach for supertall building using sensor monitoring system," Journal of Sensors, vol. 2019, Article ID 9283584, 12 pages, 2019.

[9] G. Allwood, G. Wild, and S. Hinckley, "Fiber Bragg grating sensors for mainstream industrial processes," Electronics, vol. 6, no. 4, p. 92, 2017.

[10] X. Li, C. Yang, S. Yang, and G. Li, "Fiber-optical sensors: basics and applications in multiphase reactors," Sensors, vol. 12, no. 9, pp. 12519-12544, 2012.

[11] G. B. Rajan, Optical Fiber Sensors - Advanced Techniques and Applications, CRC Press, Boca Raton, Florida, 2015, 91-93.

[12] A. Alsarhan and A. Agarwal, "Optimizing spectrum trading in cognitive mesh network using machine learning," Journal of Electrical and Computer Engineering, vol. 2012, Article ID 562615, 12 pages, 2012.

[13] O. Vermesan and P. Friess, "Internet of things strategic research and innovation agenda," in In Internet of Things: Converging Technologies for Smart Environments and Integrated Ecosystems, pp. 15-26, River Publishers, Aalborg, Denmark, 2013.

[14] B. W. Jo, R. M. A. Khan, and Y.-S. Lee, "Hybrid blockchain and Internet-of-things network for underground structure health monitoring," Sensors, vol. 18, no. 12, p. 4268, 2018.

[15] A. Abdelgawad and K. Yelamarthi, "Internet of things (IoT) platform for structure health monitoring," Wireless Communications and Mobile Computing, vol. 2017, Article ID 6560797, 10 pages, 2017.

[16] W. Zeng and H. Gao, "Optic fiber sensing IOT technology and application research," Sensors \& Transducers Journal, vol. 180, no. 10, pp. 16-21, 2014.

[17] Y. M. Gebremichael, W. Li, B. T. Meggitt et al., "A field deployable, multiplexed Bragg grating sensor system used in an extensive highway bridge monitoring evaluation tests," IEEE Sensors Journal, vol. 5, no. 3, pp. 510-519, 2005.

[18] "Latvian State Roads homepage - traffic speed sensors network," https://lvceli.lv/en/.

[19] D. Tosi, "Improved KLT algorithm for high-precision wavelength tracking of optical fiber Bragg grating sensors," Journal of Sensors, vol. 2017, Article ID 5412825, 10 pages, 2017.
[20] Y. Wang, "Application of optical fiber sensor technology in building Internet of things," Journal of Chemical and Pharmaceutical Research, vol. 6, no. 6, pp. 1151-1155, 2014.

[21] S. Spolitis, V. Bobrovs, and G. Ivanovs, "Investigation of highspeed AWG filtered spectrum-sliced WDM PON system," in 8th International Symposium on Communication Systems, Networks \& Digital Signal Processing (CSNDSP), pp. 1-4, Poznan, Poland, July 2012.

[22] ITU-T Recommendation G 694.1, "Spectral grids for WDM applications: DWDM frequency grid," in International Telecommunication Union, Telecommunication standardization sector of ITU, pp. 1-7, Geneva, Switzerland, 2002.

[23] S. Spolitis, I. Lyashuk, and V. Bobrovs, "Design and performance evaluation of FBG-based temperature sensors network," in 2017 Progress in Electromagnetics Research Symposium - Fall (PIERS - FALL): Conference Proceedings 2017, pp. 2673-2678, Singapore, Singapore, Nov. 2017.

[24] Z. A. El-Sahn, W. Mathlouthi, H. Fathallah, S. LaRochelle, and L. A. Rusch, "Dense SS-WDM over legacy PONs: smooth upgrade of existing FTTH networks," Journal of Lightwave Technology, vol. 28, no. 10, pp. 1485-1495, 2010.

[25] M. S. Leeson and S. Sun, "Spectrum slicing for low cost wavelength division multiplexing," in 2nd ICTON Mediterranean Winter: Conference Proceedings 2008, pp. 1-4, Marrakech, Morocco, Dec 2008.

[26] A. Ghazisaeidi, F. Vacondio, and L. A. Rusch, "Filter design for SOA-assisted SS-WDM systems using parallel multicanonical Monte Carlo," Journal of Lightwave Technology, vol. 28, no. 1, pp. 79-90, 2010.

[27] Z. Al-Qazwini and H. Kim, "Ultranarrow spectrum-sliced incoherent light source for 10-Gb/s WDM PON," Journal of Lightwave Technology, vol. 30, no. 19, pp. 3157-3163, 2012.

[28] T. Yamatoya and F. Koyama, "Noise suppression of spectrumsliced light using semiconductor optical amplifiers," Electronics and Communications in Japan (Part II: Electronics), vol. 86, no. 2, pp. 28-35, 2003.

[29] C. C. K. Chan, Optical Performance Monitoring: Advanced Techniques for Next-Generation Photonic Networks, ELSEVIER Inc., The Chinese University of Hong Kong, 2010.

[30] Measuring extinction ratio of optical transmitters application note 1550-8, Available online: January 2019, http://literature. cdn.keysight.com/litweb/pdf/5966-4316E.pdf. 


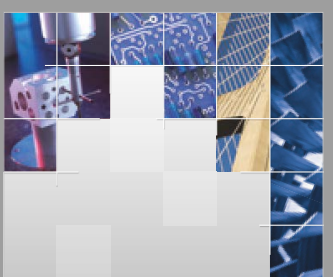

\section{Enfincering}
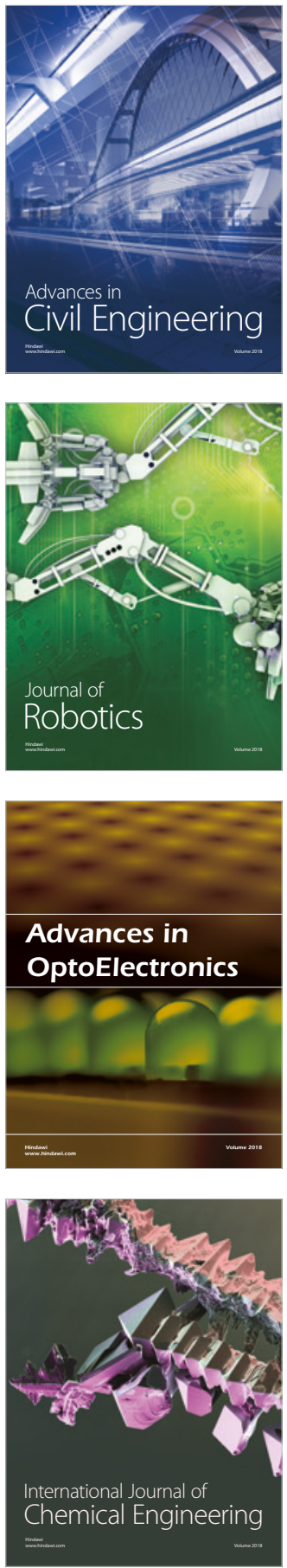

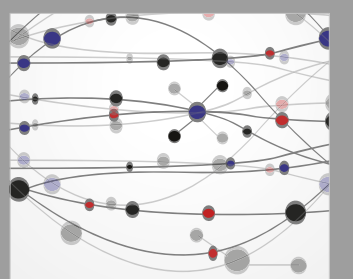

\section{Rotating \\ Machinery}

The Scientific World Journal

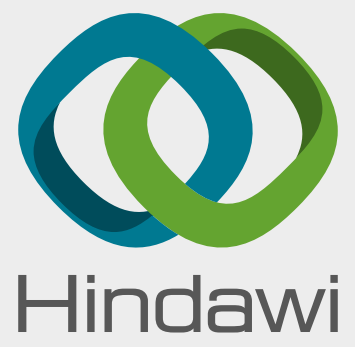

Submit your manuscripts at

www.hindawi.com
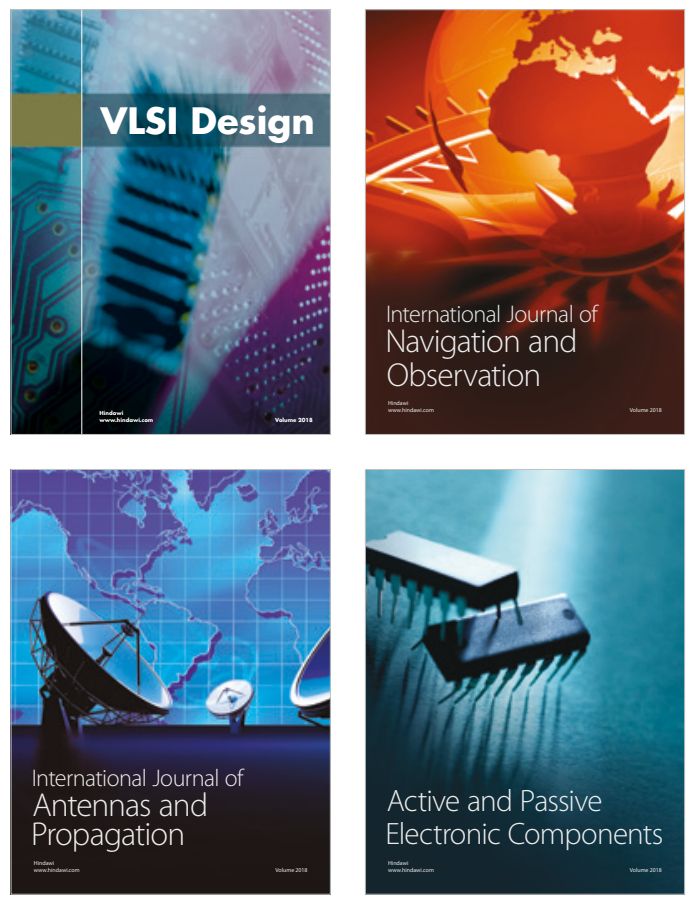
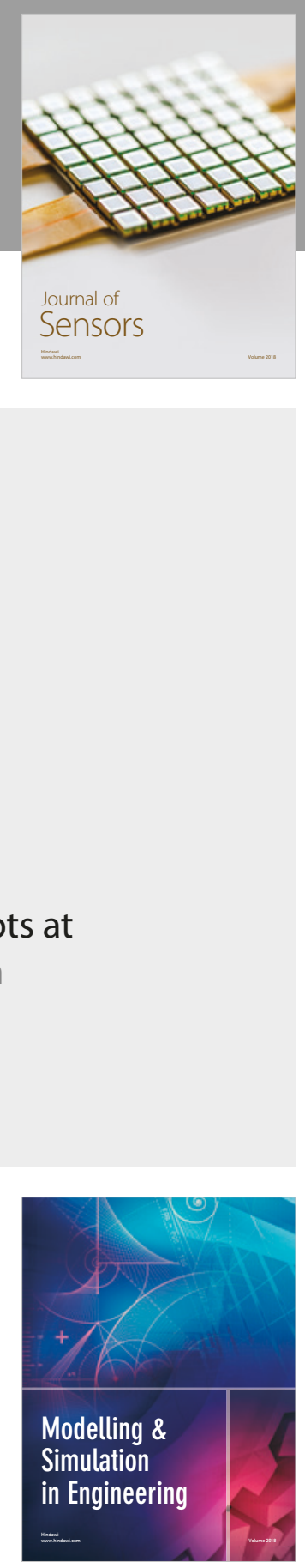

\section{Advances \\ Multimedia}
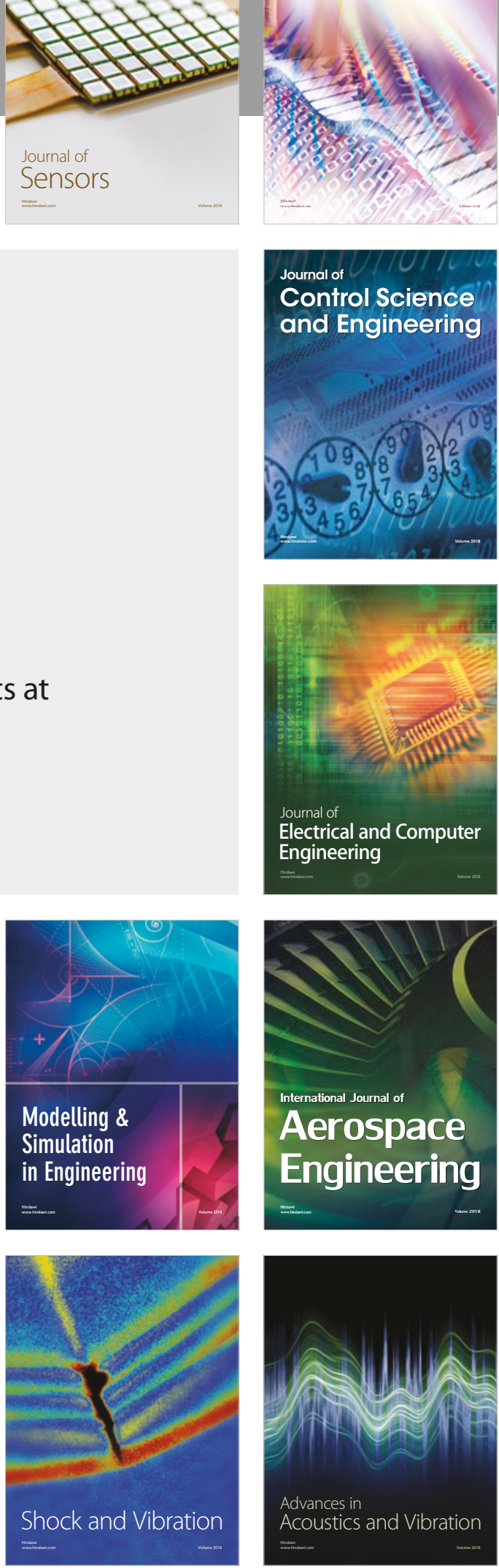